\begin{tabular}{ll}
\hline \hline MINING AND METALLURGY INSTITUTE BOR & ISSN: 2334-8836 (Štampano izdanje) \\
UDK: 622 & ISSN: 2406-1395 (Online) \\
\hline \hline
\end{tabular}

UDK: $621.221(045)=111$

doi:10.5937/mmeb1704029P

Dušan Polomčić*, Dragoljub Bajić*, Jelena Ratković*, Bojan Hajdin*

\title{
ESTIMATING HYDRAULIC PARAMETERS FOR THE COMPLEX HYDRODYNAMIC MODELS ${ }^{* *}$
}

\begin{abstract}
Hydrodynamic models have usually been calibrated manually, by trial-and-error, with different values of hydraulic parameters and hydraulic characteristics of boundary conditions. This method of calibration and estimation of hydraulic parameters requires an extensive knowledge and experience of experts, but whether the resulting solution includes an optimal set of parameters still remains an open question. An optimization method founded upon the Gauss-Marquardt-Levenberg algorithm, along with PEST software based on that algorithm, introduces automation of model calibration with regularization, which substantially reduces the effect of expert judgment on the result. The method also introduces the so-called "pilot points", which transcend the concept of homogeneous zones with the values of hydraulic parameters of a hydrogeological system or zones with the specified boundary conditions. Mineral ore deposits are the most complex in geological and hydrogeological terms, so the lignite coal mine "Tamnava - West Field" was selected as a good area to test the approach. Applying the proposed method, the spatial distributions of the horizontal $(K x=K y)$ and vertical $(K z)$ components of hydraulic conductivity are determined in the study area.
\end{abstract}

Keywords: calibration, optimization, PEST, hydraulic conductivity

\section{INTRODUCTION}

Hydrodynamic modeling is the most complex and most appealing method for simulating the aquifer regimes. It is based on numerical solving the partial differential equations that describe the groundwater flow and processes taking place in the porous medium. Hydrogeologists mainly follow this approach to assess the groundwater regime, quantify the groundwater balance, analyze the flow pattern, make the alternative prognostic calculations for a technical concept, and predict the movement of groundwater, a pollutant or heat. In the case of mineral ore deposits, the groundwater modeling is mainly used for alternative prognostic calculations made in connection with design of the groundwater control systems-lowering groundwater levels to below the elevation of mining operations [1, 2, 3]. Hydrodynamic models are also used to assess the effectiveness of groundwater control systems and select the optimal solution [4].

Calibration of the hydrodynamic model is the most delicate process in modeling, which includes fitting the groundwater flow simulation results to data recorded in nature

\footnotetext{
* University of Belgrade, Faculty of Mining and Geology, Department of Hydrogeology, Groundwater Modeling Center,e-mail: dusan.polomcic@rgf.bg.ac.rs,dragoljub.bajic@rgf.bg.ac.rs,jelena.mocevic@ rgf.bg.ac.rs, bojan.hajdin@rgf.bg.ac.rs

** Our gratitude goes to the Ministry of Education, Science and Technological Development of the Republic of Serbia for funding the Projects OII76022, TR33039 and III43004.
} 


\section{STUDY AREA}

(piezometric levels and components of the groundwater balance).

Until recently, manual calibration has been widespread; it involves a trial-and-error with different combinations of model parameter values, to fit the estimated model parameter values to those observed in nature. Such approach to a hydrodynamic model calibration requires a vast experience and extensive knowledge, while the ultimate solution has a distinct expert judgment component [5]. However, the automated calibration, using a special-purpose software, has been gaining ground over the past several years. This approach optimizes the values of select parameters of the hydrogeologic system: hydraulic conductivity, specific yield and specific storage. It also optimizes the values of boundary conditions, such as the rates of infiltration and evapotranspiration, discharges, piezometric levels and the like. The optimization method is based on the Gauss-Marquardt-Levenberg algorithm [6], which looks for the minimum residual sum of squares - the difference between measured data and model simulation results.

PEST (Model-Independent Parameter Estimation and Uncertainty Analysis) software is commonly used worldwide for the automated model calibration with regularization $[7,8]$. This is the most advanced software for optimizing the parameters of any simulation model and analysis of uncertainty in prognostic calculations $[9,10]$. PEST is widely used in geoscience $[11,12,13]$.

Mineral ore deposits are the most complex case of hydrodynamic modeling of aquifer regimes. The complexity of such areas is attributable to the dynamics - continuous changes in the model's flow field corroborated by a constant expansion of deposits. In the present research, the optimization approach to the estimation of hydraulic parameters in hydrodynamic modeling was applied to the largest open-cast mine in Serbia - the lignite coal mine of Tamnava West Field. Hydraulic conductivity (K) was estimated by this complex analysis.
The Tamnava - West Field coal mine belongs to the Kolubara Coal Basin. To the west and south the mine borders on the Radljevo open - cast mine, and to the east on the Tamnava - East Field open-cast mine. On the northern side, there is a natural boundary where the coal bed lenses out. The geologic framework in the paleo relief is comprised of the Paleozoic and Mesozoic sediments, while the coal basin itself is built up of the Neogene deposits: alluvial and terrace sediments of the Kolubara, Kladnica, Turija and Peštan rivers (Fig. 1). There are also other sediments, such as diluvial-proluvial and oxbow deposits. Quaternary sediments discordantly overlie the Pontian strata $\left(\mathrm{Pl}_{1}\right)$.

The Tamnava - West Field is the largest open-cast mine in Serbia, where lignite coal is mined. A total of $11,600,000$ tons of coal was extracted in 2015 , which was $15.5 \%$ more than the annual budget.

\section{METHODOLOGY}

The methods used in this research were the hydrodynamic modeling and the GaussMarquardt-Levenberg algorithm [6] for optimization. PEST software, based on the said algorithm, was used for estimation. The concept required the introduction of pilot points $[7,8,9,10]$, which did not necessarily signify fictitious points, although the points at which some of the parameters were known were relatively few. Each pilot point represented a parameter whose value was to be determined. The concept of pilot points is not restricted to hydraulic conductivity; it applies to all parameters determined during the course of model calibration.

There are several ways in which the pilot points can be specified in the model, such as by means of a regular grid or triangulation [7]. The use of pilot points in PEST is referred to as regularization, whereby the distribution of certain parameters and/or values of boundary conditions are regularized. The outcome of this approach in 
PEST calibration is a result that includes the heterogeneity of the medium (flow field) with regard to the distribution of the determined parameters of the medium (hydraulic conductivity in the present case).

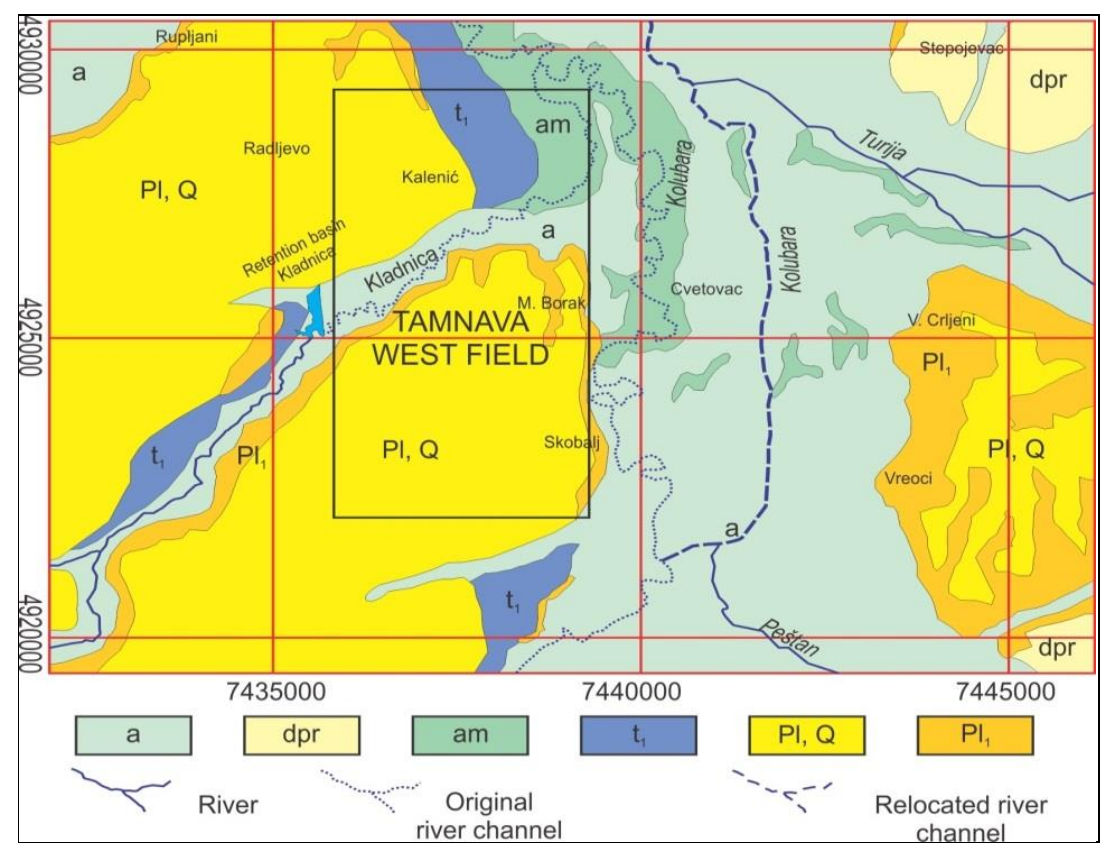

Figure 1 Geological map of the open-cast mine Tamnava - West Field (according to the national geological map of Serbia, scale 1:100,000, Obrenovac section and [14])

Legend: a - riverbed sediments; dpr - diluvial/proluvial sediments; am - oxbow sediments; $t_{l}$ - lower river terrace; $Q, P l$ - riverine-lacustrine terrace; $P l_{l}$ - sand and clay (marly and coaly).

\section{RESULTS}

A three-dimensional hydrodynamic model of the Tamnava - West Field, based on the method of finite differences, was developed using the MODFLOW code [15] with the Groundwater Vistas Advanced graphic user interface, version 64-Bit 6.74 b.24 [16]. It was designed as a multi-layer model, with a total of eight layers (Table 1), as described in [17]. Each of these layers corresponded to a real layer, modeled on the basis of the results of analyses of in situ investigations. The initial values of hydraulic conductivity for all the lithologic units were entered based on the outcomes of in situ hydrogeological investigations and are shown in Table 1.
Both manual and automated (PEST with regularization option) calibration of the model was undertaken. Pilot points were specified for automated calibration, given that they help to obtain much more realistic heterogeneous zones with hydraulic conductivities. Figure 2 shows the model layers in which pilot points were specified. They were used to determine the spatial distribution of the horizontal $(\mathrm{Kx}=\mathrm{Ky})$ and vertical $(\mathrm{Kz})$ components of hydraulic conductivity. No pilot points were specified in the $6^{\text {th }}$ model layer represented solely by the second coal bed. A total of 729 pilot points were specified with the horizontal component and 286 with the vertical component of hydraulic 
conductivity. The way the pilot points were specified depended on the hydro-geological significance of the various sediments and the number and distribution of piezometers in the water-bearing layers (Table 1 and Fig. 2 ). In the case of semi-permeable sediments, a homogeneous grid of pilot points was specified for each distinct lithologic unit. On the other hand, the pilot points for water-bearing sediments with piezometers were specified by triangulation between three neighboring piezometers, with an additional pilot point in the center of each triangle. Then the density was increased in the parts where the pilot points were located. In the $8^{\text {th }}$ model layer, a so-called regular grid of pilot points, spaced $500 \mathrm{~m}$ apart, was specified. The pilot points determining a distribution of vertical component of hydraulic conductivity were moved $50 \mathrm{~m}$ relative to the horizontal component, to display the points more easily.

Determined representative values of hydraulic conductivity were the outcome. A total of 49,964 zones with values of hydraulic conductivity were identified in the model of Tamnava - West Field. Figure 3 shows the hydraulic conductivities of the model layers. The results are presented as the maps of hydraulic conductivity distribution, with different color fields according to a color scale. The data generated by the software can also be exported to xls and presented in tabular form.

Table 1 Schematic view of the flow field - representation of the lithologic units in the model layers with initial values of hydraulic conductivity $\left(K_{x}, K_{y}, K_{z}\right)$

\begin{tabular}{|l|l|c|c|}
\hline \multicolumn{1}{|c|}{ Model layer } & \multicolumn{1}{|c|}{ Lithologic units } & $\mathbf{K}_{\mathbf{x}}=\mathbf{K}_{\mathbf{y}}(\mathbf{m} / \mathbf{s})$ & $\mathbf{K}_{\mathbf{z}}(\mathbf{m} / \mathbf{s})$ \\
\hline $\begin{array}{l}\text { First confining } \\
\text { layer (stratum) }\end{array}$ & $\begin{array}{l}\text { Quaternary clay and heterogeneous } \\
\text { mine waste in the northern part of the } \\
\text { area }\end{array}$ & $5 \times 10^{-6}$ & $5 \times 10^{-7}$ \\
\hline $\begin{array}{l}\text { Second com- } \\
\text { bined water- } \\
\text { bearing - }\end{array}$ & Upper aquifer sand and gravel & $5 \times 10^{-4}$ & $5 \times 10^{-5}$ \\
\hline \multicolumn{1}{c|}{ confining layer } & $\begin{array}{l}\text { and heterogeneous mine waste in the } \\
\text { northern part of the area }\end{array}$ & $1 \times 10^{-6}$ & $1 \times 10^{-7}$ \\
\hline $\begin{array}{l}\text { Third confining } \\
\text { layer }\end{array}$ & $\begin{array}{l}\text { Aleurites and mine waste in the } \\
\text { northern part of the area }\end{array}$ & $5 \times 10^{-6}$ & $5 \times 10^{-7}$ \\
\hline $\begin{array}{l}\text { Fourth confining } \\
\text { layer }\end{array}$ & First coal bed & $5 \times 10^{-9}$ & $5 \times 10^{-10}$ \\
\hline $\begin{array}{l}\text { Fifth combined } \\
\text { water-bearing - }\end{array}$ & $\begin{array}{l}\text { Intermediate aquifer sands in the } \\
\text { western and central parts in front of } \\
\text { the mine contour } \\
\text { Heterogeneous mine waste in the north- } \\
\text { ern part of the area, clay sediments in } \\
\text { the north-eastern part and coals in the } \\
\text { eastern and southern parts of the area }\end{array}$ & $1 \times 10^{-5}$ & $5 \times 10^{-6}$ \\
\hline Confining layer & Second coal bed & $5 \times 10^{-6}$ & $1 \times 10^{-7}$ \\
\hline $\begin{array}{l}\text { Sixth confining } \\
\text { layer }\end{array}$ & $\begin{array}{l}\text { Lower aquifer sands of high } \\
\text { hydraulic conductivity } \\
\text { bearing layer }\end{array}$ & $\begin{array}{l}\text { Lower aquifer sands of low } \\
\text { hydraulic conductivity }\end{array}$ & $5 \times 10^{-10}$ \\
\hline $\begin{array}{l}\text { Eighth water- } \\
\text { bearing layer }\end{array}$ & $5 \times 10^{-5}$ & $5 \times 10^{-6}$ \\
\hline
\end{tabular}



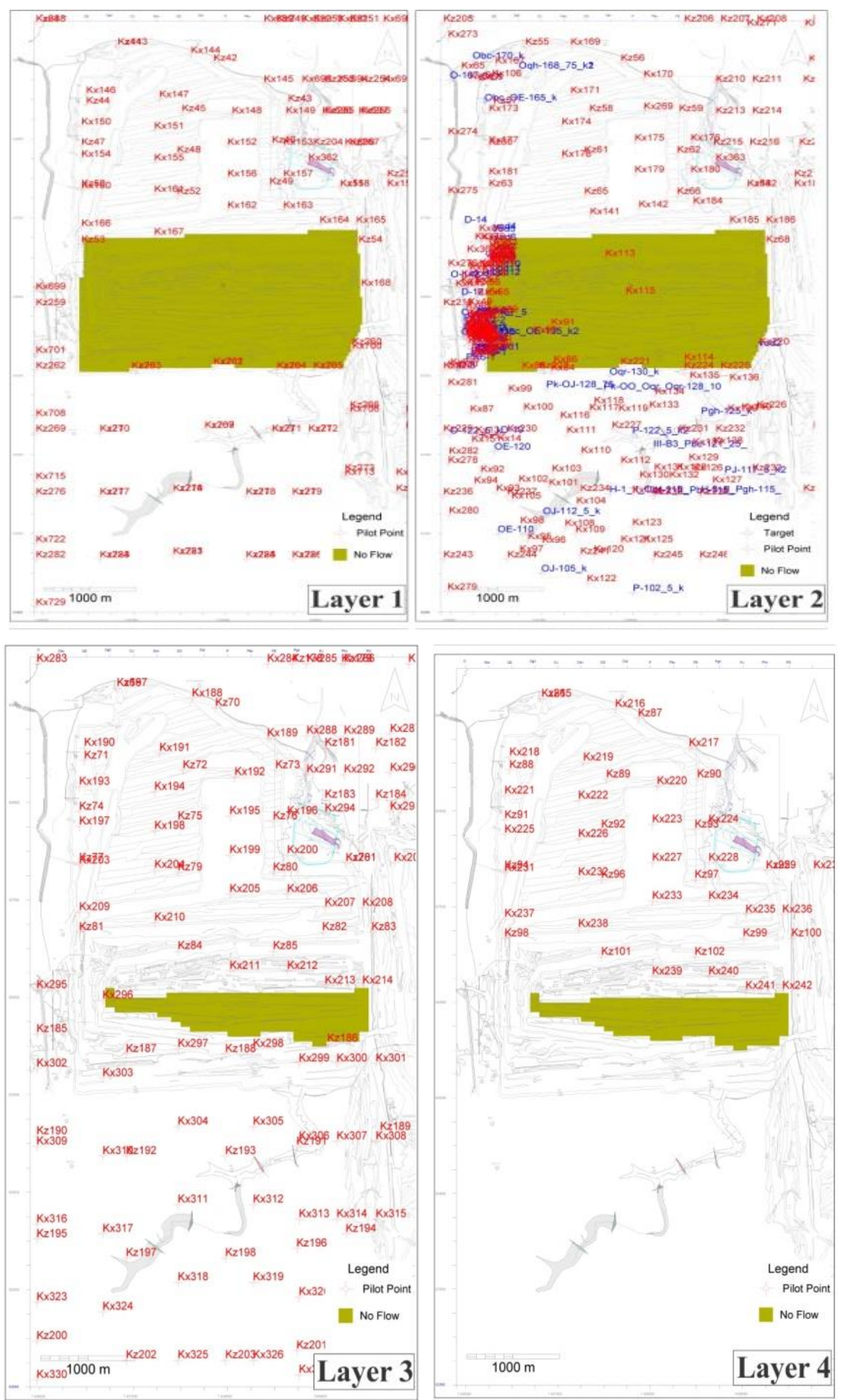

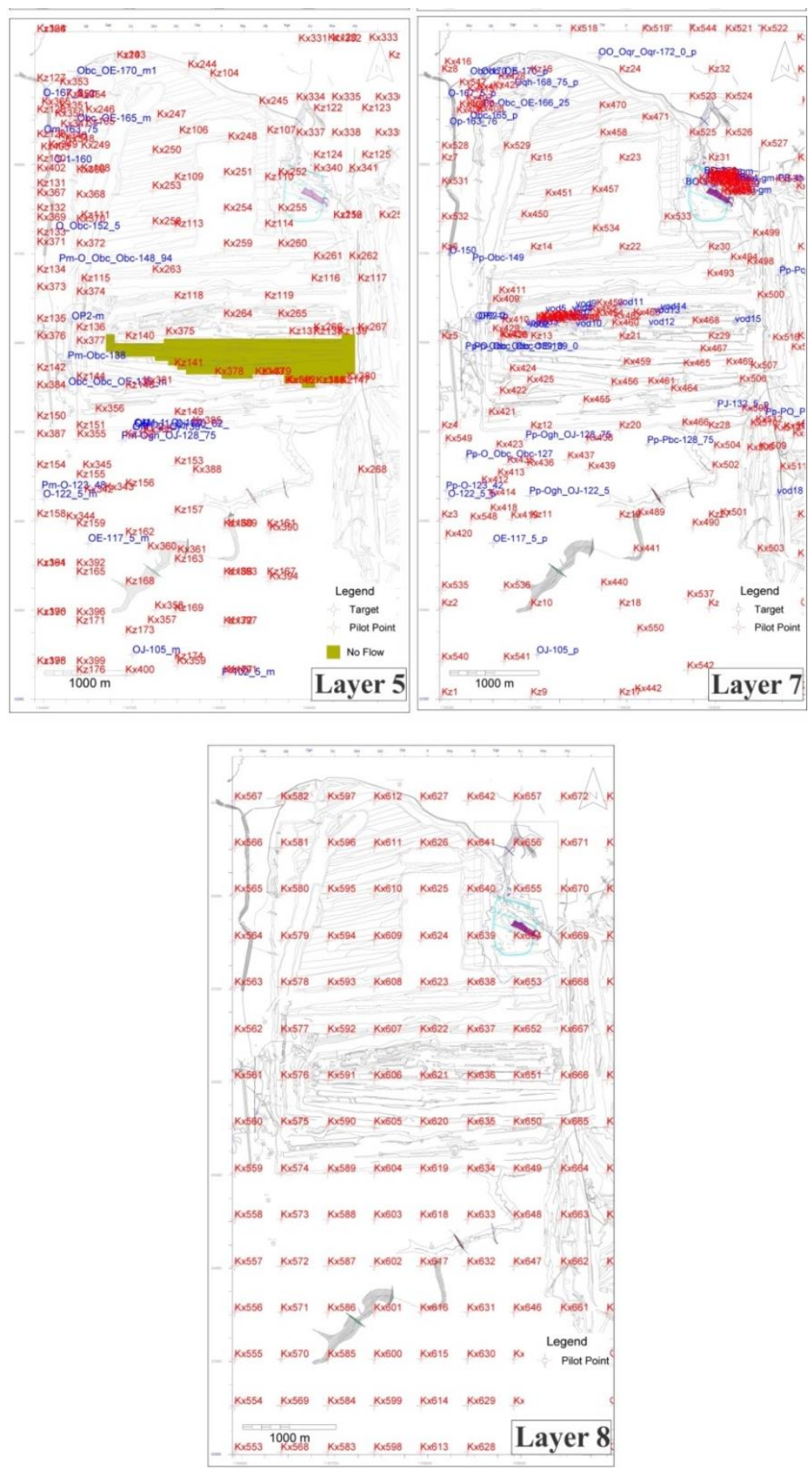

Figure 2 Distribution of pilot points in the model layers of the Tamnava - West Field open-cast mine 

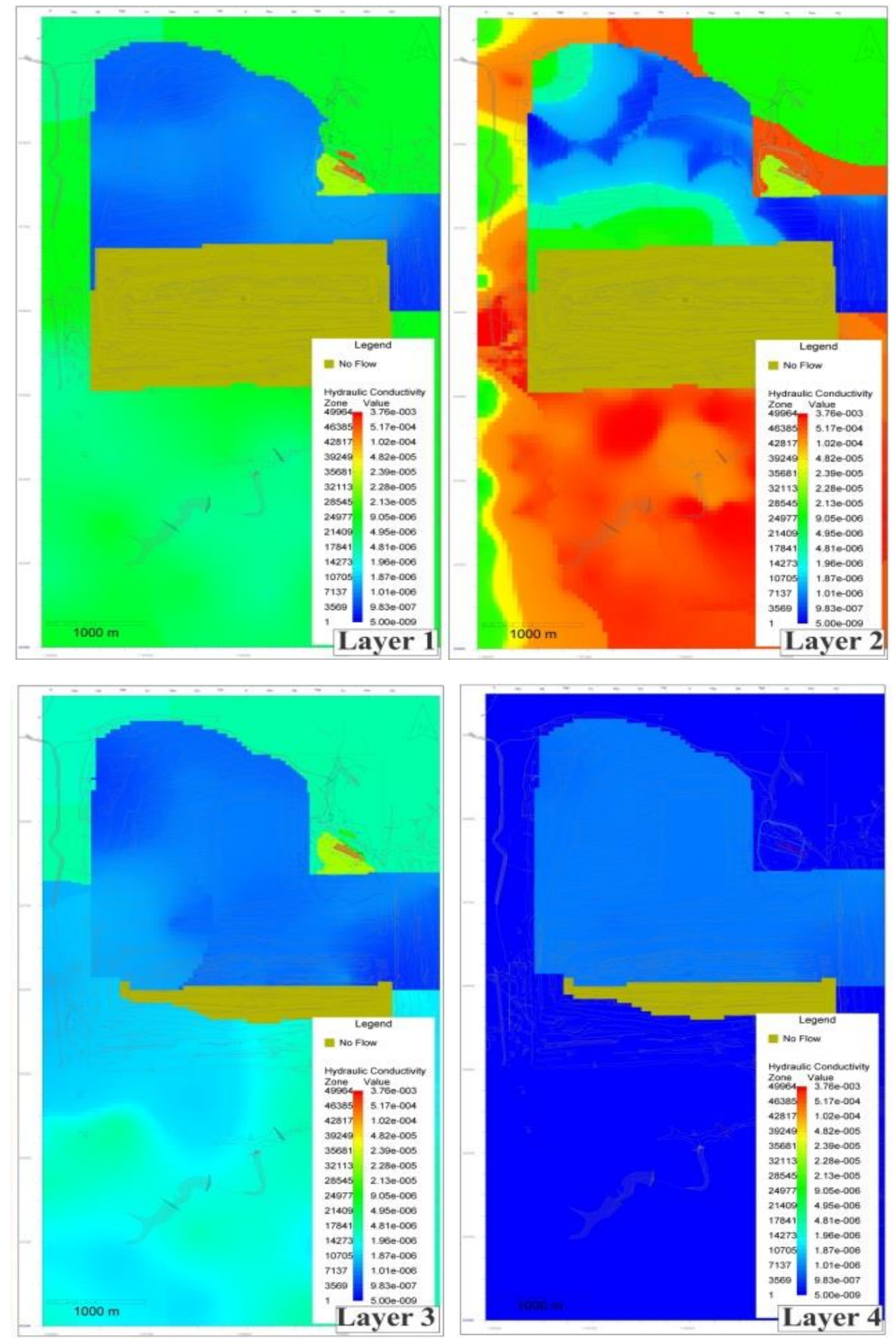

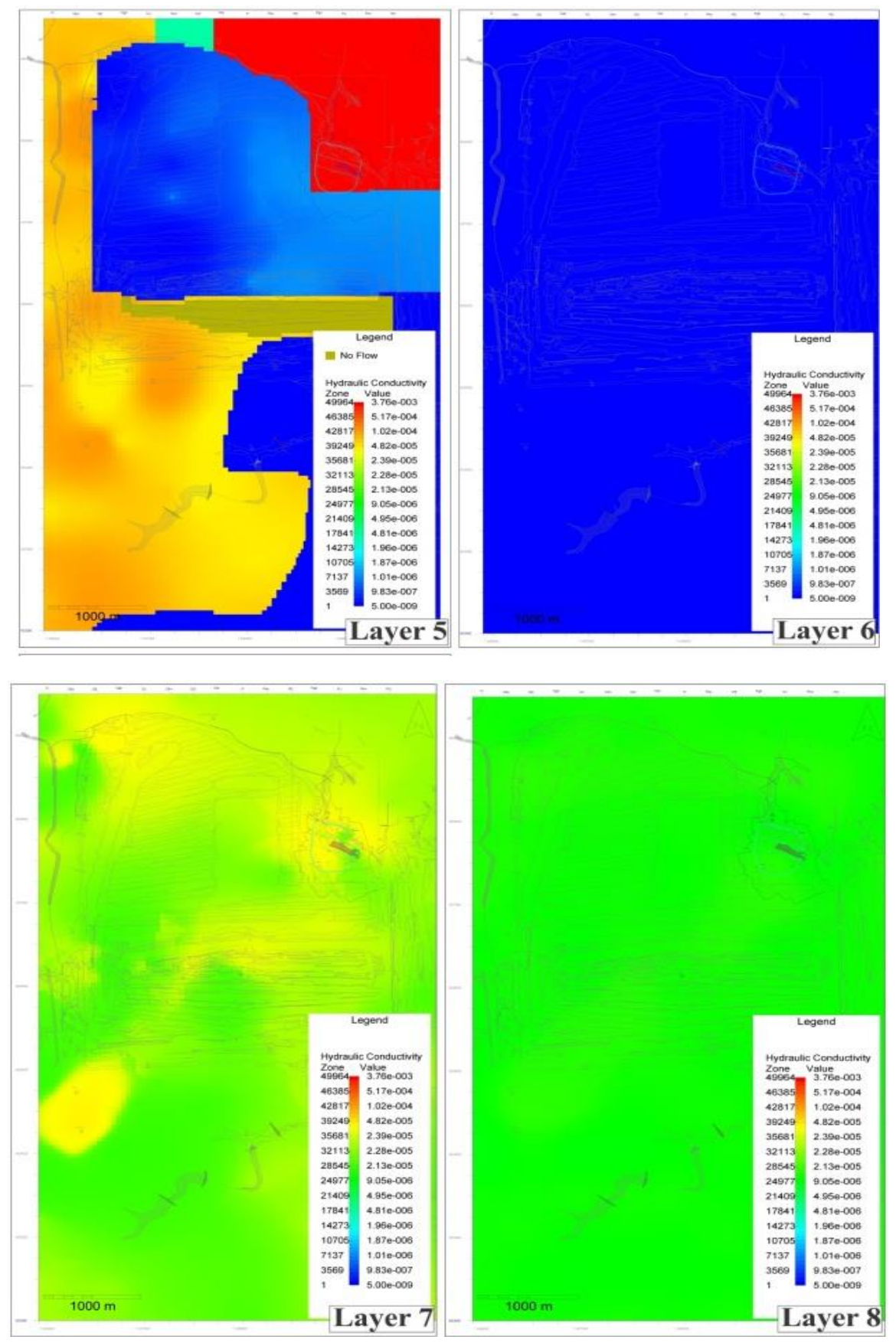

Figure 3 Zones of hydraulic conductivity in the model layers of the Tamnava - West Field open-cast mine 


\section{CONCLUSION}

The paper described the application of an optimization method based on the GaussMarquardt - Levenberg algorithm in hydrodynamic modeling, undertaken to assess a hydraulic conductivity during the course of automated calibration with regularization. The method considerably reduces the influence of expert judgment on the result. PEST software was used to optimize the parameters during the automated calibration process. This software has a broad range of applications, which transcend groundwater modeling. A development of PEST introduced the concept of pilot points, which surpasses that of homogeneous zones with values of parameters of the medium or zones with specified boundary conditions. Even though the concept is a big step forward in the estimation of hydraulic parameters in hydrodynamic modeling, there are some issues. One of the biggest problems in connection with the use of pilot points in PEST is the needed computation time. Every increase in the number of pilot points in the model considerably lengthens the calibration time. Namely, PEST considers each pilot point as a parameter whose optimum value is to be determined. It should be noted that in PEST, each parameter requires one or two simulations per iteration. The described model of the Tamnava - West Field coal mine had a total of 1015 pilot points, which meant 1015 simulations (or 2030 if central differentiation was used) per iteration. A larger number of iterations per run were often needed during model calibration. If each run takes several minutes, then a long of time is needed to complete the process. The calibration time is measured in hours, and sometimes in days. However, there is certainly a solution for this problem and the use of modules that shorten the com- putation time (Parallel PEST, BeoPEST, Cloud Computing and Singular Value Decomposition) is expanding.

\section{REFERENCES}

[1] Polomčić D., Bajić D., Papić P., Stojković J. (2013). Hydrodynamic Model of the Open-Pit Mine "Buvač" (Republic of Srpska). Journal of Sustainable Development of Energy, Water and Environment Systems, 1(3): 260271. DOI: http://dx.doi.org/10.13044/ j.sdewes.2013.01.0019

[2] Polomčić D. \& Bajić D. (2015). Application of Groundwater Modeling for Designing a Dewatering System: Case Study of the Buvač Open Cast Mine, Bosnia and Herzegovina. Geologia Croatica, 68(2):123-137. DOI: $10.4154 /$ gc.2015.07

[3] Rapantova N., Grmela A., Vojtek A., Halir J. \& Michalek B. (2007). Ground Water Flow Modelling Applications in Mining Hydrogeology. Mine Water and the Environment, 26 (4): 264-270.

[4] Bajić D., Polomčić D. \& Ratković J. (2017). Multi-Criteria Decision Analysis for the Purposes of Groundwater Control System Design. Water Resources Management, DOI: 10.1007 /s11269-017-1777-4

[5] Polomčić D., Bajić D., Ristić-Vakanjac V. \& Čokorilo Ilić M. (2014). Automatic Calibration of Hydrodynamic Models Using PEST Program. Zapisnici Srpskog Geološkog Društva, pp. 13-27.

[6] Nocedal J. \& Wright J.S. (2006). Numerical Optimization, 2nd Edition. Springer: Berlin 
[7] Doherty J. (2010). PEST - ModelIndependent Parameter Estimation, User Manual: 5th Edition, Watermark Numerical Computing, pp. 1-336

[8] Doherty J. (2013). Addendum to the PEST Manual, Watermark Numerical Computing, pp. 1-294.

[9] Doherty E. J., Hunt J. R. (2010). Approaches to Highly Parameterized Inversion: A Guide to Using PEST for Groundwater-Model Calibration, Scientific Investigations Report 2010 5169, U.S. Geological Survey, Reston, Virginia.

[10] Doherty E.J., Hunt J.R. \& Tonkin M.J. (2011). Approaches to Highly Parameterized Inversion: A Guide to Using PEST for Model-Parameter and Predictive-Uncertainty Analysis. Scientific Investigations Report 2010-5211. U.S. Geological Survey, Reston, Virginia.

[11] Tonkin M.J., \& Doherty E.J. (2005). A Hybrid Regularized Inversion Methodology for Highly Parameterized Environmental Models. Water Resources Research, DOI: 10.1029/ 2005WR 003995.

[12] Bahremand A. \& De Smedt F. (2010). Predictive Analysis and Simulation Uncertainty of a Distributed Hydrological Model. Water Resources Management, 24(12): 2869-2880.

[13] Bezak N., Rusjan S., Petan S., Sodnik J. \& Mikoš M. (2015). Estimation of
Soil Loss by the WATEM/SEDEM Model Using an Automatic Parameter Estimation Procedure. Environmental Earth Sciences, 74(16): 5245-5261.

[14] Hayley K., Schumacher J., MacMillan G.J. \& Boutin L.C. (2014). Highly Parameterized Model Calibration with Cloud Computing: An Example of Regional Flow Model Calibration in Northeast Alberta, Canada. Hydrogeology Journal, 22(3): 729-737

[15] Ratković J., Polomčić D., Bajić D. \& Hajdin B. (2016). A Hydrogeological Model of the Open-Cast Mine Tamnava - West Field (Kolubara Coal Basin, Serbia). Underground Mining Engineering, 29: 43-54.

[16] Harbaugh A. W., Banta E. R., Hill M. C.\&McDonald M.G. (2000) MODFLOW - 2000: The U.S. Geological Survey Modular Ground-Water Model - User Guide to Modularization Concepts and the Ground-Water Flow Process, U.S. Geological Survey OpenFile Report 00-92, Reston, VA, USA

[17] Rumbaugh J.O. \& Rumbaugh D.B. (2011). Guide to Using Groundwater Vistas: Version 6. New York: Environmental Simulations

[18] Polomčić D., Bajić D., Ratković J., Šubaranović T. \& Ristić Vakanjac V. (2017). Hydrodynamic Model of the Open-Cast Mine "Tamnava - West Field” (Kolubara Coal Basin, Serbia). 